\title{
DESAFÍOS ÉTICO-ECONÓMICOS QUE PLANTEA LA ENCÍCLICA LAUDATO SI'
}

\section{ETHICAL AND ECONOMIC CHALLENGES POSED BY ENCYCLICA LAUDATO SI'}

\section{LUIS A. PANCHI VASCO ${ }^{1}$}

Recibido: 28 de junio de 2016 Aprobado: 20 de febrero de 2017

\footnotetext{
${ }^{1}$ Pontificia Universidad Católica del Ecuador, Dirección de Pastoral Universitaria, Quito, Ecuador, (lapanchi@puce.edu.ec.).
} 



\section{DESAFÍOS ÉTICO-ECONÓMICOS QUE PLANTEA LA ENCÍCLICA LAUDATO SI'}

\section{ETHICAL AND ECONOMIC CHALLENGES POSED BY ENCYCLICA LAUDATO SI'}

Luis A. Panchi Vasco

PALABRAS CLAVES: ética, Laudato si', economía, límites planetarios, antropoceno, institucionalidad

KEY WORDS: ethics, Laudato si', economy, planetary boundaries, anthropocene, institutions

\section{RESUMEN}

La Encíclica Laudato si', en el contexto de una crisis ecológica planetaria, plantea tres retos económicos: 1. Una nueva economía teórica y práctica que recoja el principio de la moderación en la producción y el consumo y que además, de endogenizar los costos ecológicos, sea un instrumento para el servicio de la vida. 2. Una nueva institucionalidad nacional y global que se efectúe como justicia en los aportes para la mitigación del cambio climático, de manera que los países industriales más contaminantes paguen más y se reconozca los servicios ambientales de los pobres. 3. Una nueva concepción del ser humano, que supere el antropocentrismo y lo valore en su especificidad junto con los otros seres del mundo, dejando de lado el uso instrumental de la naturaleza a fin de conservarla para las futuras generaciones. 


\section{ABSTRACT}

The Encyclical Laudato si' in the context of a global ecological crisis poses three economic challenges: 1. A new theoretical and practical economics to reflect the principle of moderation in production and consumption and also to endogenize ecological costs. It is economics as instrument for the service of life. 2. New national and global institutions that implement justice in contributions to mitigating climate change, so that the most polluting industrial countries pay more and to acknowledge the environmental services of the poor countries. 3. A new conception of the human being, overcoming anthropocentrism and to value human being in their specificity with other beings in the world, leaving aside the instrumental use of nature in order to preserve it for future generations.

\section{INTRODUCCIÓN}

La encíclica Laudato si' (en adelante Ls), del papa Francisco, plantea desafíos éticos a la humanidad y a la forma en que la humanidad se entiende y vive en el mundo: nuestra casa común. Esos desafíos nos tocan a todos y en todas las esferas de realización humana: política, cultural, social, económica, nacional e internacional.

En este artículo se afrontarán los desafíos éticos en la dimensión económica. El modo de ser persona en el mundo hoy está transido por la mediación económica que, en muchos casos, pierde su dimensión instrumental para pasar a convertirse en finalidad misma de la existencia de las personas.
Sin duda que la crisis ecológica planetaria que vivimos, exige plantearnos una nueva economía, tanto en la teoría como en la práctica. Los niveles de consumo, producción, explotación y distribución de recursos no pueden permanecer inalterados si queremos realmente conservar nuestro planeta como lo hemos conocido.

Aquí se sustenta la tesis que un sincero compromiso por la conservación del planeta y de la vida en él, implica tres aspectos fundamentales: un diferente aprovechamiento del mundo, una nueva institucionalidad nacional y global, junto con una nueva concepción de ser humano en el mundo. 
El método empleado parte de una presentación sucinta de los fenómenos problemáticos más urgentes hacia la eliminación de sus causas. Para ello se recurre a los datos estadísticos más significativos y las proyecciones más relevantes. Es la primera parte metodológica de la misma encíclica: el ver. La segunda parte corresponde al juzgar y se desarrolla como una reflexión sobre la nueva economía necesaria para superar las contradicciones actuales del sistema económico. Para la tercera parte, la del actuar, se propone líneas de acción colectiva e individual.

El asunto, como cuestión ética, queda abierto al diálogo intersubjetivo y a la construcción consensuada de propuestas.

\section{DATOS QUE INDICAN LA APROXIMACIÓN DE UNA CATÁSTROFE ECOLÓGICA}

Considerando la realidad del mundo actual, hay datos que nos urgen a mejorar las condiciones del planeta, bastante deteriorado ecológicamente y a causa de la acción del ser humano.

En el año 2000, los científicos Eugene Stoermer y el premio Nobel en química Paul Crutzen propusieron nombrar a nuestra época, como el período geológico antropoceno. En los próximos milenios y a causa de las emisiones humanas de dióxido de carbono, el clima en nuestro planeta se desviaría significativamente de su desarrollo natural, tal la fundamentación de la propuesta por parte de los científicos (Müller, 2015: 4).

A partir de la revolución industrial, la acción humana, sobre todo económica, estaría modificando la evolución natural de nuestro planeta. La indus- trialización habría superado los límites de renovación o resiliencia del planeta, tanto a causa del consumo como de la producción de bienes, que implican la explotación desmedida de los recursos naturales.

El incremento de la temperatura media del planeta desde la revolución industrial hasta la fecha, sería el indicador clave de un cambio climático con consecuencias funestas para los ecosistemas y el mismo ser humano. De continuar esta tendencia, la vida en el planeta no volverá a ser la misma, la desaparición de especies, el aumento del nivel de los mares, el desgaste del suelo, las grandes migraciones animales, microbiológicas, vegetales y humanas cambiarán la faz de la tierra.

Pese a los grandes esfuerzos internacionales por contener el calenta- 
miento global, la emisión de dióxido de carbono creció en los últimos 30 años más de lo que los escenarios más pesi- mistas de la conferencia mundial sobre el clima, habían previsto.

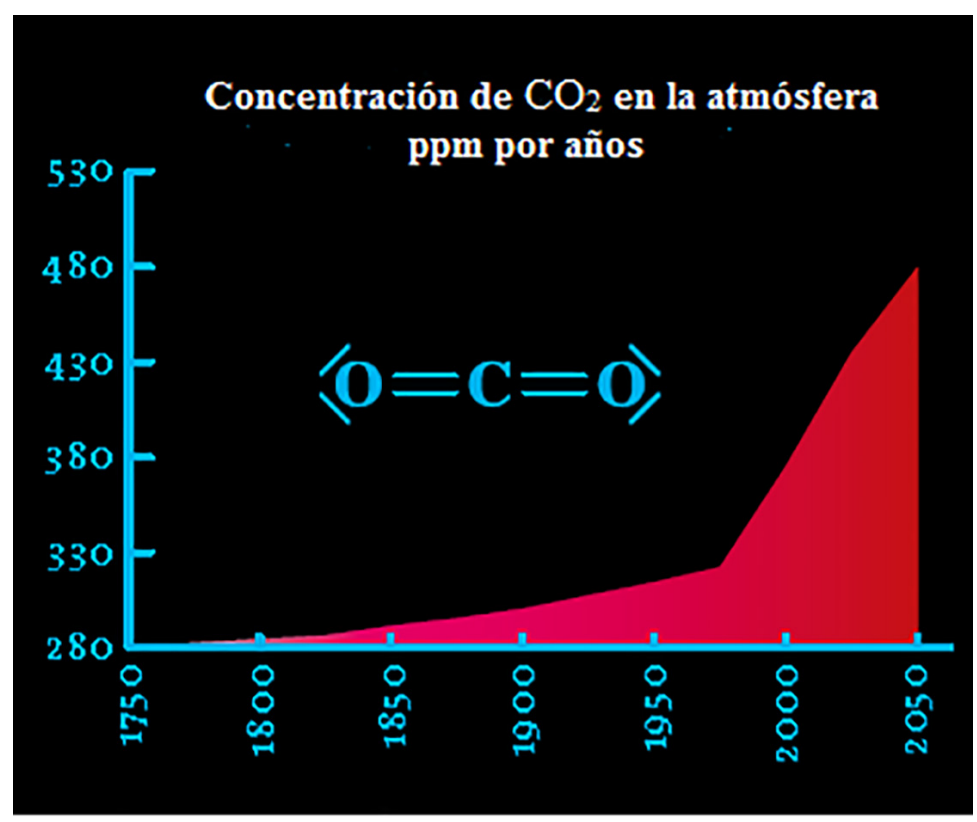

Figura 1: Concentración de $\mathrm{CO}_{2}$ en la atmósfera.

Fuente: movum. Briefe zur Transformation, 2015: 6-7. Adaptación propia.

Un equipo de 18 científicos alrededor del Instituto Potsdam para investigación de las consecuencias climáticas (PIK en alemán) publica en la revista Science 347, que cuatro de los llamados nueve "límites planetarios" han sido ya rebasados o sea hemos entrado en etapa de peligro: 1) cambio climático con una concentración actual de $\mathrm{CO}_{2}$ de 400 ppm, 2) extinción de especies con una tasa mayor a 100 especies por millón de especies por año, 3) ciclo del nitrógeno en el suelo con 121 millones de toneladas por año y 4) ciclo del fósforo en el suelo con 9,5 millones de toneladas al año (movum. Briefe zur Transformation, 2015: 10). 

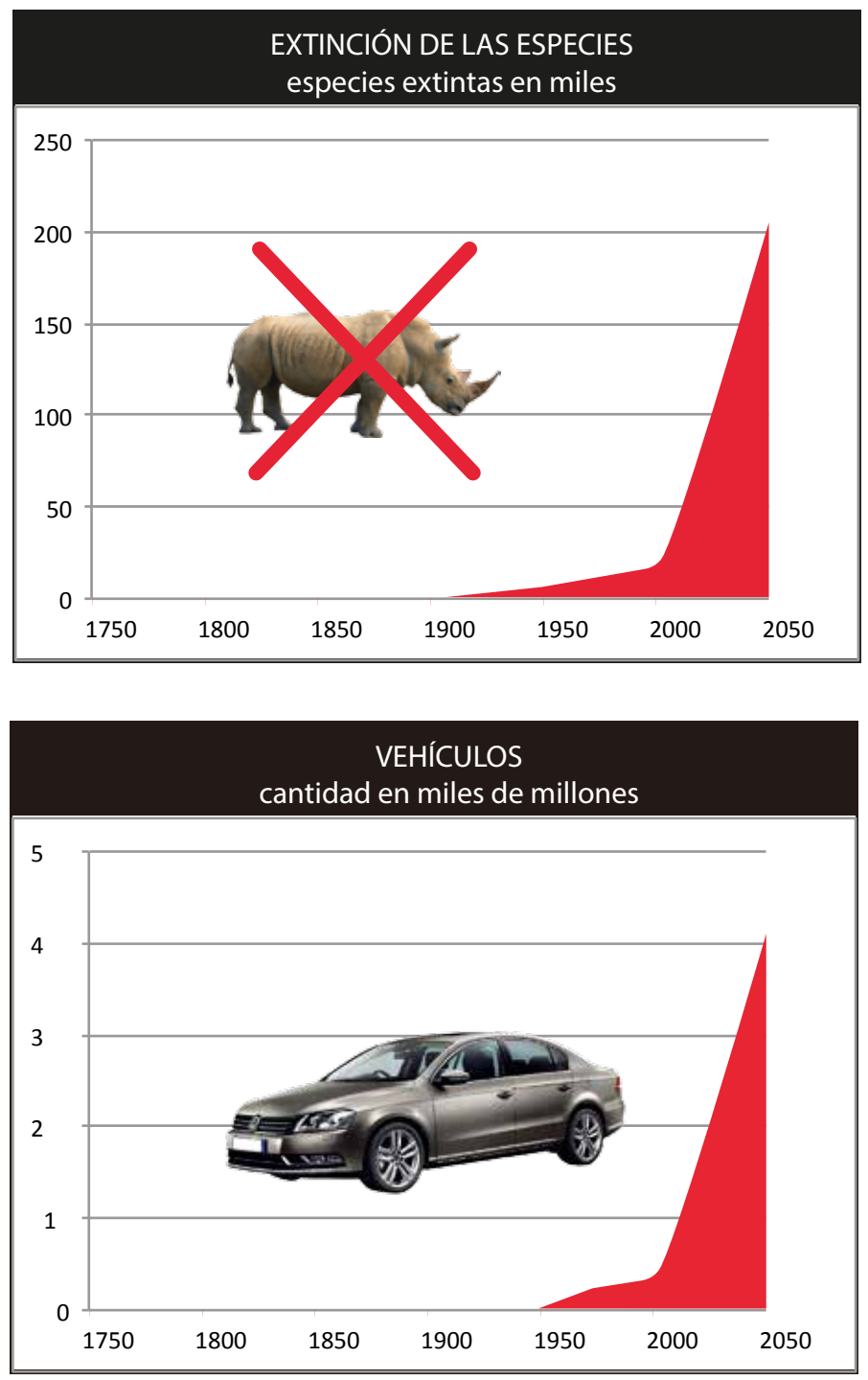

Figura 2: Extinción de especies y aumento de vehículos a nivel mundial.

Fuente: movum. Briefe zur Transformation. 2015: 6-7. Adaptación propia. 
De 1967 a 2011, en tan solo 44 años, se duplicó la población mundial hasta los 7 mil millones; se triplicó el uso de energía y cuadruplicó las emisiones de dióxido de carbono. A la humanidad le habría tomado alrededor de 200000 años llegar al primer mil millones, pero solo le tomó 200 llegar a 8 veces los mil millones.

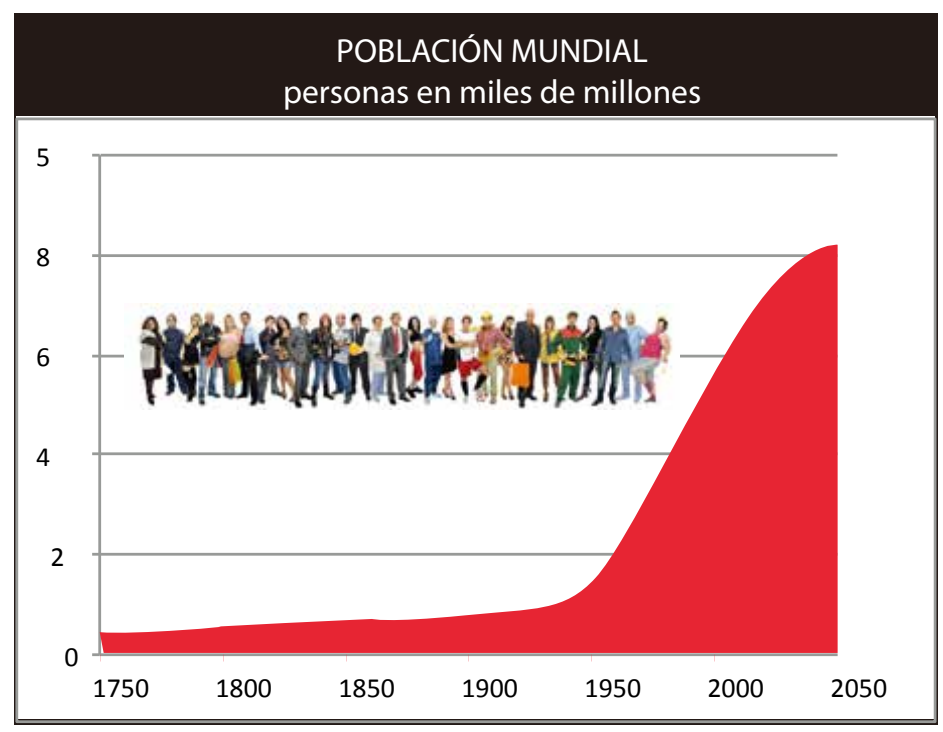

Figura 3: Crecimiento de la población mundial.

Fuente: movum. Briefe zur Transformation, 2015: 6-7. Adaptación propia.

Ante estas amenazas climáticas, urge una transformación en el modo de aprovecharse de nuestro planeta. De él extraemos cuanto necesitamos para vivir, pero no nos hemos limitado a vivir sino que nos hemos extendido a consumir sin medida. La virtud cristiana de la frugalidad es hoy más urgente que nun- ca. Moderación en el consumo, respetar ciclos naturales de largo plazo y no pretender agotar recursos con la velocidad que la economía actual nos pone a competir. Requerimos otro tipo de economía, tanto teórica como práctica.

Los intentos de una nueva economía van desde la asimilación de otros 
factores económicos como el tiempo, los ecosistemas, los costos externalizados, la comunidad, etc. Hasta la propuesta de nuevos objetivos que orienten las finalidades económicas: buen vivir, conservación ecológica, solidaridad, libertad de autorrealización, independencia del trabajo, crecimiento cero, etc.

\section{UN DIFERENTE APROVECHARSE DEL MUNDO: NUEVA ECONOMÍA}

Nos encontramos frente a una "ruptura civilizatoria" (Falconí, 2011: 125), debemos como humanidad vivir, producir y consumir de otro modo. Sin comprometer la subsistencia de nuestro planeta. No se puede seguir pretendiendo crecimiento económico al infinito en una biósfera limitada. Con recursos naturales finitos el crecimiento económico sin fin es un absurdo. Se requiere de una nueva "racionalidad ambiental" (Leff, 2000 y 1994).

El papa Francisco (2015) hace un llamado a "la necesidad de búsqueda de un desarrollo sostenible e integral" $(L s, 13)$. En el fondo se trata de otro desarrollo, con nuevas características. Si antes primó la competencia, el lucro, el cortoplacismo, el capital, la maximización de beneficios y la minimización de costos, la externalización de los costos sociales y ambientales; hoy la encíclica da pie a pensar un desarrollo basado en la solidaridad de los pueblos, la relativización de la ganancia individual a favor de la social, la mirada de largo plazo que involucre a las futuras generaciones, la revalorización del trabajo y el tiempo, la eficacia y la eficiencia sujetas a la ética social y la limitación del consumo.

La "cultura del descarte" (Ls, 22) implica la práctica de producir basura masivamente y la falta de procesos para asumir ese desperdicio dentro de la producción, uso y etapa posterior al uso de los productos. Son escasas las industrias que se preocupan por dar un tratamiento al producto obsoleto o acabado. Desgraciadamente, esta idea de lo desechable se extiende también hacia las personas, descartadas por los sistemas sociales y económicos.

"Limitar al máximo el uso de los recursos no renovables, moderar el consumo, maximizar la eficiencia del aprovechamiento, reutilizar y reciclar" (ibid.) y reducir (las 3Rs) son las propuestas hacia un mundo más limpio, con mayor calidad de vida y más justo.

El cambio climático tiene también como causa un "patrón de desarrollo basado en el uso intensivo de com- 
bustibles fósiles, que hace al corazón del sistema energético mundial" (Ls, 23). Los combustibles fósiles como medios de combustión son los que más gases de efecto invernadero emiten a la atmósfera. Sin embargo, la industria en general, la locomoción y la producción de calor y de energía no pueden dejar de lado la combustión de hidrocarburos por razones económicas y subvenciones (Schlegelmilch, 2015: 8).

La tecnología para reemplazar a los hidrocarburos está lista, no así la economía que los asuma en los costos de los procesos de producción. Todavía los combustibles fósiles son baratos o más bien no integran en sus precios los costos medioambientales y sociales que provocan.

Las buenas prácticas son escasas pero necesarias: "inversiones en formas de producción y de transporte que consumen menos energía y requieren menos cantidad de materia prima, así como en formas de construcción o de saneamiento de edificios para mejorar su eficiencia energética" (Ls, 26).

Por otra parte, la estructura económica exige que las nuevas tecnologías sean rentables y que las antiguas cumplan su ciclo de vida, agotando sus posibilidades de rendimiento económico, si no es en sus países de origen, sí en los países a los que se exporta la tecnología caduca.
Los países en vías de desarrollo consumen la tecnología que los países desarrollados ponen a su disposición, y, generalmente, no es la de punta sino la reemplazada. Dada la asimetría en la producción de ciencia y tecnología, incluso en las tecnologías de energías limpias o más eficientes, los países pobres deben comprarlas a los países industriales, quienes obtienen un doble beneficio de esta estructura antiecológica y segregacionista. Por un lado, con la anterior tecnología, han logrado elevados niveles de rendimiento gracias a la contaminación del planeta; por otro, una vez que la tecnología es caduca, la venden a los países pobres que podrán mejorar sus rendimientos y ambiente de modo marginal.

Al final del día, quienes sufren los peores déficits ecológicos, económicos y de salud humana son los países pobres. El elevado nivel de vida de los países ricos se manifiesta también en la buena calidad del aire, alimentos sanos, disponibilidad de agua potable, disfrute de la naturaleza con seguridad para ello y acceso a lugares apropiados para la vida y el descanso, libres de basura, ruidos y contaminantes. Bienes que no están disponibles en igual medida en los países pobres.

Los costos de la crisis ecológica y el cambio climático no se distribuyen en proporción a quienes más contaminan el planeta. Las naciones industriales gene- 
ran el $80 \%$ de los gases de efecto invernadero (Reimer, 2015: 14). Con sus sistemas de producción y consumo masivos, con su voraz explotación de los recursos naturales aportan poco al alivianamiento de las consecuencias de la contaminación generada por sus mismos productos. Por décadas se han negado a asumir compromisos concretos para reducir la emisión de gases contaminantes, calculando que las medidas de reducción de gases de efecto invernadero contenidas en el protocolo de Kyoto les costaría hasta el 2\% de su PIB (IPCC, 2001: 56).

Los jardineros del planeta, los países subdesarrollados $y$, dentro de ellos, los pueblos originarios (Ls, 146) donde se conservan las más grandes extensiones de naturaleza prístina, deben pagar o renunciar a su cultura y territorio ya sea por megaproyectos extractivistas, ya sea por las nuevas tecnologías energéticamente más eficientes y limpias. No reciben ningún pago empero por el cuidado que hacen de las grandes regiones naturales, conservadas como santuarios ecológicos: la amazonia, la selva tropical, los humedales, las sabanas, tundras, glaciares, extensas playas y desiertos donde la presencia humana es escasa pero que requieren de atención, vigilancia, limpieza y recursos económicos.

"Hay una verdadera «deuda ecológica», particularmente entre el Norte y el Sur, relacionada con desequilibrios co- merciales con consecuencias en el ámbito ecológico" (Ls, 51). De diversas maneras, los pueblos en vías de desarrollo, donde se encuentran las reservas más ricas de la biósfera, siguen alimentando el desarrollo de los países ricos. "Es necesario que los países desarrollados contribuyan a resolver esta deuda limitando de manera importante el consumo de energía no renovable y aportando recursos a los países más necesitados para apoyar políticas y programas de desarrollo sostenible" (Ls, 52).

Dentro de una mirada social, cabe la corresponsabilidad de admitir una deuda ecológica desde el norte hacia el sur, donde se mire que quienes menos contaminan y más cuidan el planeta, porque están naturalmente ligados a la tierra, son los pobres del sur. La deuda ecológica cuestiona las deudas financieras con que muchos países del sur están atados al norte.

En una carrera técnico-científica resulta cada vez más caro mejorar tecnología anticontaminante en el norte, mientras que es más efectivo mejorar la incipiente tecnología del sur para hacerla menos contaminante. Los grandes jardines prístinos de la humanidad se concentran en el sur, son los pulmones de la humanidad y los habitantes del norte no pagan a los jardineros del sur por mantener esos jardines. El reconocimiento del bienestar ecológico mundial debe signi- 
ficar también un reconocimiento financiero de los esfuerzos del sur por mantener la naturaleza y un flujo de capitales para tal mantenimiento.

Desgraciadamente, ese apoyo no se ve en la práctica y más bien los recursos internacionales han disminuido ostensiblemente (Reimer, 2015: 14). Lo que sí ha aumentado es el volumen de exportaciones de los países industriales hacia el resto de países, y entre ellas como se puede observar en el gráfico 2, los automotores. La extinción de especies desde 1950 se ha incrementado exponencialmente, paralelamente y al mismo ritmo ha incrementado el número de vehículos a nivel mundial. Es como si los humanos estuviéramos reemplazando animales únicos en su especie por vehículos. El efecto es mundial, los productores de vehículos son pocos pero no asumen en sus costos la destrucción ambiental que generan.

El papa Francisco advierte también sobre

la mentira de la disponibilidad infinita de los bienes del planeta, que lleva a «estrujarlo» hasta el límite y más allá del límite. Es el presupuesto falso de que «existe una cantidad ilimitada de energía y de recursos utilizables, que su regeneración inmediata es posible y que los efectos negativos de las manipulaciones de la naturaleza pueden ser fácilmente absorbidos» (Ls, 106).

Se requiere de un nuevo estilo de vida. Requerimos «una nueva economía más atenta a los principios éticos y para una nueva regulación de la actividad financiera especulativa y de riqueza ficticia» (Ls, 189). Hay que entender que «desacelerar un determinado ritmo de producción y de consumo puede dar lugar a otro modo de progreso y desarroIlo. Los esfuerzos para un uso sostenible de los recursos naturales no son un gasto inútil, sino una inversión que podrá ofrecer otros beneficios económicos a mediano plazo» (Ls, 191).

Para efectivizar una nueva economía se requiere además una nueva arquitectura institucional global que descienda a las particularidades nacionales. Esto significa también un modo nuevo de hacer política, «no se puede justificar una economía sin política» (Ls, 196).

\section{NUEVA INSTITUCIONALIDAD NACIONAL Y GLOBAL}

Cambiar el modo de aprovecharse del mundo es una cuestión urgente, pues el tiempo apremia y la investigación climática global advierte que esta- 
mos ante una transformación definitiva de nuestro planeta. Los índices contenidos en la figura 1 indican el avance del cambio climático dado el aumento sin precedentes de la concentración de dióxido de carbono en la atmósfera. Según los expertos, este índice se esperaba alcanzarlo dentro de 30 años, pero se ha adelantado como nadie lo suponía.

El agotamiento de los suelos gracias a la agricultura industrial, el uso de fertilizantes con base en nitrógeno y fósforo, provoca a su vez mayores emanaciones y escape de metano a la atmósfera, agravando el efecto de calentamiento global. La extinción de especies se ha acelerado, no es que no haya habido antes extinciones masivas, ni que no deba haber. El problema es la velocidad con la que hoy acontecen. La desaparición de especies significa un cambio radical en los ecosistemas, lo cual pone en riesgo la misma sobrevivencia del sur humano sobre la tierra.

Los líderes mundiales, personas, países y organizaciones -entre ellas la Iglesia Católica- tienen responsabilidad de sus acciones y enseñanzas no solo frente a sus ciudadanos y asociados sino frente a todos los habitantes del planeta. Incorporar esta responsabilidad en la institucionalidad global y nacional es el desafío ético por excelencia en época del calentamiento global.
La conservación del planeta no es solo un reto para las generaciones presentes sino también una responsabilidad de justicia frente a las generaciones futuras. ¿Qué planeta dejaremos a los hijos de nuestros hijos? En la línea del informe Bruntland de 1986, es necesario "atender las necesidades de las generaciones actuales incluyendo a todos, sin perjudicar a las generaciones futuras" (Ls, 53).

\section{La justicia intergeneracional}

no es una cuestión que se deba dejar al tiempo sino una tarea para el presente. La responsabilidad social y ambiental que tenemos implica reconocer hoy el derecho que tienen las generaciones futuras a satisfacer sus necesidades en el uso de los recursos y gozo del planeta. Para ello hace falta desarrollar una institucionalidad nacional y global que garantice la subsistencia de tales recursos.

Hoy parece existir a nivel global una conciencia creciente de los límites planetarios. Esa conciencia se expresa como una gran preocupación por reducir los índices de contaminación sobre todo de los gases de efecto invernadero. De tal manera que los países que antes se negaron a firmar el Protocolo de Kioto, hoy toman un rol bastante activo para promover la reducción del calentamiento global o cambio climático. Los límites de soporte de la tierra han sido alcanzados y ante una posible catástrofe 
ecológica planetaria, los líderes globales se ven obligados a reaccionar.

En un récord de compromiso, 175 países firmaron el Acuerdo de París el 22 de abril de 2016. El Acuerdo exige a todos los países que adopten medidas. "Los países presentaron oficialmente sus propias medidas de lucha contra el cambio climático establecidas a escala nacional". (ONU, 2016).

188 países, responsables casi del $100 \%$ de las emisiones mundiales, presentaron sus contribuciones a nivel nacional para el logro del objetivo de mantener el aumento de temperatura global por debajo de los $2^{\circ} \mathrm{C}$ con respecto a la era preindustrial del siglo XVIII. Es más, se propusieron esforzarse para alcanzar $1,5^{\circ} \mathrm{C}$. "Para que el acuerdo entre en vigor se necesita ahora que al menos 55 países, que sumen en total el $55 \%$ de las emisiones globales, completen el proceso de ratificación" (EFE, 2016). Precisamente los países que más contaminan como son Estados Unidos y China se han comprometido a completar esos procesos este mismo año.

La ecología social es necesariamente institucional y alcanza progresivamente las distintas dimensiones que van desde el grupo social primario, la familia, pasando por la comunidad local y la nación, hasta la vida internacional (Ls, 142).

Para afrontar los problemas de fondo, que no pueden ser resueltos por acciones de países aislados, es indispensable un consenso mundial que lleve, por ejemplo, a programar una agricultura sostenible y diversificada, a desarrollar formas renovables y poco contaminantes de energía, a fomentar una mayor eficiencia energética, a promover una gestión más adecuada de los recursos forestales y marinos, a asegurar para todos el acceso al agua potable (Ls, 164).

La Cumbre de la Tierra, celebrada en 1992 en Río de Janeiro, consagró la cooperación internacional para cuidar el ecosistema de toda la tierra, la obligación por parte de quien contamina de hacerse cargo económicamente de ello, el deber de evaluar el impacto ambiental de toda obra o proyecto. Propuso el objetivo de estabilizar las concentraciones de gases de efecto invernadero en la atmósfera para revertir el calentamiento global. También elaboró una agenda con un programa de acción y un convenio sobre diversidad biológica, declaró principios en materia forestal. Si bien aquella cumbre fue verdaderamente superadora y profética para su época, los acuerdos han tenido un bajo nivel de implementación porque no se establecieron adecuados mecanismos de control, de revisión periódica y de sanción de los incumplimientos. Los principios enunciados siguen reclamando caminos eficaces y ágiles de ejecución práctica (Ls, 167). 
El comercio de emisiones de carbono no ha dado los frutos esperados. Los precios vigentes estarían 20 veces por debajo de los precios reales (Staude, 2015: 12). La especulación con precios a la baja, favorece a las empresas y países que más contaminan.

A nivel financiero queda mucho por hacer. En las negociaciones previas al Acuerdo de París, ha encontrado muy poca acogida la idea de un impuesto para las emisiones de dióxido de carbono que superen cierto límite (Mahnke y Götze, 2015: 13). No existe además la infraestructura global capaz de controlar y coaccionar la emanación de gases contaminantes. Se ha dejado a voluntad de los países y su legislación nacional, la adopción de medidas para mitigar el calentamiento global. Las mismas, hoy, se muestran insuficientes.

En la estructura financiera global, a nivel público y privado, se premia con los mayores rendimientos a las inversiones directas y adyacentes a los combustibles fósiles. Las inversiones en energías renovables son pocas y sin nivel de competencia con las fósiles.

La justicia es también justicia en la distribución de los costos actuales para la conservación del planeta y la reducción de la masa de gases de efecto invernadero. Algunas de las estrategias de baja emisión de gases contaminantes buscan la internacionalización de los costos ambientales, con el peligro de imponer a los países de menores recursos pesados compromisos de reducción de emisiones comparables a los de los países más industrializados. La imposición de estas medidas perjudica a los países más necesitados de desarrollo. De este modo, se agrega una nueva injusticia envuelta en el ropaje del cuidado del ambiente... «los países que se han beneficiado por un alto grado de industrialización, a costa de una enorme emisión de gases invernaderos, tienen mayor responsabilidad en aportar a la solución de los problemas que han causado» (Conferencia Episcopal Boliviana, 2012: 86, citado por Ls, 170).

\section{UNA NUEVA CONCEPCIÓN DE SER HUMANO EN EL MUNDO}

El período antropoceno significa que la presencia y la acción humana influyen de tal modo en el planeta, que no es factible entender la historia física del planeta y sus cambios sin recurrir al ser humano como factor explicativo de esos cambios, a nivel geológico, climático, ecosistémico. Según este concepto, 
en los últimos tres siglos, a partir de la revolución industrial, la presencia humana habría sido determinante para tener el tipo de planeta que tenemos y que tendremos.

Este acontecimiento plantea un nuevo desafío ético, el de una nueva comprensión de sí mismo de parte del ser humano. Si antes primó la relación instrumental con la tierra ahora debemos buscar una relación vincular. La tierra es nuestra "casa común", es la casa donde constituimos nuestro "mundo de la vida". Un mundo que no solo ofrece lo necesario para la propia existencia sino que más allá de satisfacción de necesidades, nos proyecta a vivir en armonía con lo y los demás. No estamos solos. Los elementos de la naturaleza nos acompañan y nos constituyen. Los demás, los otros, los animales, vegetales e inertes nos especifican la existencia, nos enseñan el mundo y nos permiten ser humanos.

Los árboles, la tierra, el agua, los elementos del paisaje y los animales son elementos constitutivos de esta casa común, como lo somos también nosotros, los humanos. Las bacterias, los virus, los hongos son elementos sustanciales de los ecosistemas, ellos preceden a las formas de vida más complejas y en algún sentido las sustentan. El ser humano debe su existencia a la evolución silenciosa de estos elementos y por tanto debe respetar sus espacios y existencias particulares.

El cuidado del ambiente es también cuidado de los demás, romper la autoreferencialidad, salir del individualismo del actual sistema económico y social hacia una mirada orgánica y comunitaria. Las redes humanas son las que dan sentido a toda otra red tecnológica, los vínculos humanos son los que anteceden a todo otro vínculo instrumental.

El respeto, la acogida, el reconocimiento mutuo, son los valores esenciales de una existencia humana feliz. Son los fundamentos de una sociedad plenamente humana. Frente a un ecologismo que pretenda colocar al ser humano como un animal más entre todos los existentes, que lo ubique como una especie destinada a la extinción como tantas otras que han sido sobre la faz de la tierra, desde la ética podemos y debemos resaltar la unicidad del ser humano y su conciencia como reconocimiento del otro. Somos seres racionales en la medida que somos morales y la moralidad es una condición de posibilidad que precede a la razón.

Frente a la actitud invasiva y dominante de la era de la razón instrumental, le corresponde a esta nueva era de la razón ética una actitud respetuosa y valorativa de los entes que habitan con nosotros, quienes hacen parte de la casa común o biósfera. Una comprensión de 
sí, que valore las capacidades humanas en el contexto de la vida en el planeta y que valore también las otras vidas, distintas de la humana.

En una visión de sí que relativiza su posición de privilegio, el ser humano no se pierde como un ente más entre todos los que conforman el universo, pero tampoco se coloca en la cúspide como referencia total y absoluta. Una visión ecológica de sí, comprende que para ser humanos requerimos del entorno biológico y físico del cual extraemos nuestro sustento y con el cual satisfacemos nuestras necesidades. Agotarlo, destruirlo, ensuciarlo, extinguirlo en cualquiera de sus formas, es simplemente autodestruirnos. El ser humano no al centro ni en la cúspide de todo sino integrado en el todo, con conciencia de límites individuales y como especie.

"No hay ecología sin una adecuada antropología" (Ls, 118). Una visión de sí mismo de parte del ser humano implica una visión del mundo. "El ser ahí" (Heidegger, 1988) en el mundo es ciertamente una especificación de la existencia en el mundo como lo conocemos, la referencialidad del ser humano a la tierra; evolucionando el ser humano evoluciona la tierra, cambiando la tierra cambia el ser humano; no entendemos un ser humano sin la tierra aunque es posible imaginarse una tierra sin ser humano, como nos lo enseña la geología.
El ser humano se objetiva en los instrumentos que emplea para su sobrevivencia, son instrumentos "a la mano" del hombre (Heidegger, 1988: 78). Entre los instrumentos complejos, las instituciones deben permitirnos una existencia mutuamente satisfactoria donde el poseer quede relegado al ser, donde el consumir esté al servicio del vivir, donde no se enajene el tiempo propio a favor de una organización empresarial que consume nuestras vidas sino se lo emplee en la autodeterminación del modo individual de ser humano.

La capacidad de "salir de sí hacia el otro" (Ls, 208) para una existencia mutuamente autorrealizadora y sustentable es también un reto ético para una nueva concepción de humanidad. Dejar de lado la individualidad del sistema económico y buscar elementos comunitarios de vida es parte de una nueva visión de sí mismo del ser humano.

Los creyentes, en particular, requieren también actualizar su fe hacia una "conversión ecológica" para convertirse en "protectores de la obra de Dios" (Ls, 217). "Superar la lógica de la razón instrumental" (Ls, 219).

La urgencia de la crisis ecológica implica comprender que a problemas sociales se responde con redes comunitarias, no con la mera suma de bienes individuales. «Las exigencias de esta tarea van a ser tan enormes, que no hay forma 
de satisfacerlas con las posibilidades de la iniciativa individual y de la unión de particulares formados en el individualismo. Se requerirá una reunión de fuerzas y una unidad de realización» (Guardini, 1958: 93, citado por Ls, 219). La vida en común y el bienestar común requieren de una lógica distinta a la suma de los bienes individuales.

Si me va bien a mí y a mi vecino y al otro vecino, no necesariamente nos va bien a todos. El bien particular posiciona del mejor modo a cada uno dentro de las condiciones dadas. El bien común es capaz de cambiar las condiciones dadas. El bien recíproco no significa tener la mejor casa o el mejor auto, significa tener los mejores servicios: agua potable, alcantarillado, luz eléctrica, etc. El bien común es de otra naturaleza que la suma de bienes particulares, requiere de instituciones reconocidas por todos $y$ conducentes al beneficio social porque relativizan el beneficio individual.

El pueblo de Gera, al sur del Ecuador, habitado por familias de migrantes a los Estados Unidos, tiene hermosas casas construidas con planos norteamericanos, jacuzzi, balcones y cuarto de servicio. Una casa hermosa al lado de otra se podría pensar que al pueblo de Gera le va muy bien y que tienen un alto bienestar común. Pero la suma de utilidades individuales no corresponde a la utilidad del bien común. El pueblo de
Gera no tiene alcantarillado, agua potable, adoquinado ni asfaltado de calles, la energía eléctrica es deficiente lo mismo que los servicios de salud y educación. Su cultura además es diferente de aquella de donde se copiaron los planos y los jacuzzis. Sin agua, los jacuzzis se han convertido en cuyeras. Aunque sus habitantes invierten para el beneficio individual no tienen las suficientes inversiones para el beneficio recíproco.

La lógica económica vigente, promoviendo el beneficio particular externaliza los costos del medioambiente. Esto significa dejar a otros los costos provocados por la contaminación de suelos, ríos y mares. Dejar a los más pobres los costos de la sobrepesca, de la contaminación del aire, de la producción de basura. Costos que adquieren la forma de enfermedades respiratorias, de la piel o cáncer, cuyo tratamiento debe pagar cada uno de los afectados y en el mejor de los casos, los sistemas de protección social gubernamentales. Por ello, «la protección del medio ambiente deberá constituir parte integrante del proceso de desarrollo y no podrá considerarse en forma aislada» (ONU, 1992: Principio 4, citado por Ls, 141). Transferir los costos ambientales a los pobres o a la ciudadanía o a sus sistemas sociales y dejar los beneficios de la ganancia para la iniciativa privada, va en contra del principio ético social de justicia. 
Los países industriales con sus elevados índices de producción y consumo deben buscar caminos para reducir la carga que su producción de bienes y servicios ejerce sobre el planeta. Sobre todo la explotación de hidrocarburos. Hoy más que nunca la virtud aristotélica de la moderación se muestra necesaria para conservar la naturaleza tal como la conocemos ahora.

Cuando pensamos en la situación en que se deja el planeta a las generaciones futuras, entramos en otra lógica, la del don gratuito que recibimos y comunicamos. Si la tierra nos es donada, ya no podemos pensar solo desde un criterio utilitarista de eficiencia y productividad para el beneficio individual. No estamos hablando de una actitud opcional, sino de una cuestión básica de justicia, ya que la tierra que recibimos pertenece también a los que vendrán (Ls, 159).

Simplemente se trata de redefinir el progreso. Un desarrollo tecnológico y económico que no deja un mundo mejor y una calidad de vida integralmente superior no puede considerarse progreso (Ls, 194). Redefinición que implica un nuevo modo de comprenderse como ser humano en el mundo. Ser persona y no elemento del mercado. Sujeto de necesidades por satisfacerse a través del consumo, no sujeto del consumo. Sujeto con conciencia de la limitación personal y de los recursos naturales. Persona actor de la economía y no mero agente de transformación económica. Entender la economía como interpretación adecuada a la satisfacción de las necesidades humanas y no como sistema autónomo con leyes cuasi naturales.

Entonces todo acto económico y toda relación productiva, incluyendo la explotación de recursos naturales es un acto moral. Toda acción económica implica un juicio moral. «Comprar es siempre un acto moral, y no solo económico »(Benedicto XVI, 2009: 699, citado por Ls, 206). Por eso, hoy «el tema del deterioro ambiental cuestiona los comportamientos de cada uno de nosotros». (Benedicto XVI, 2010: 48 citado por Ls, 206).

\section{CONCLUSIONES}

Ante la grave crisis ecológica del mundo actual, que ya se plantea como una catástrofe climática global, La encíclica Laudato si recoge tres desafíos ético-económicos básicos.
Primero, la necesidad de un nuevo y diferente modo de aprovecharse del mundo, esto es una nueva economía tanto teórica como práctica. El supuesto económico de un crecimiento infinito 
con recursos naturales limitados es una ficción absurda. La relación del ser humano con el mundo no puede ser básicamente de explotación sino de conservación y cuidado del planeta y la vida dentro de él. La economía al servicio de la vida (Ulrich, 2008) implica moderar el consumo, promover las energías renovables, endogenizar los costos ecológicos externalizados y proyectar la producción de bienes incluyendo la disposición de su destino final. Evitar la generación de basura, de gases contaminantes, el agotamiento de los suelos y la explotación de los más pobres son las directrices para una nueva economía.

Segundo, el cuidado del planeta exige una nueva institucionalidad nacional e internacional. Los compromisos nacionales para la reducción del calentamiento global son insuficientes. Se requiere de órganos de control y coacción supranacional. La justicia inter y transgeneracional no puede estar fuera de los debates por una nueva institucionalidad. Los costos del cuidado del planeta deben recoger el aporte de los países pobres en una suerte de "deuda ecológica" de los países ricos respecto de los países pobres, quienes conservan las mayores reservas bionaturales. La distribución de los costos ecológicos para la prevención del calentamiento global, por ejemplo, debe ser proporcional, de modo que paguen más los países ricos que más contaminan y se reconozca el aporte de las bajas emisiones contaminantes de los países pobres.

Tercero, los dos desafíos ético-económicos anteriores presuponen una nueva concepción filosófica del ser humano en el mundo. Ya no como cúspide de una pirámide biológica sino como elemento constitutivo del mundo, junto a los otros seres orgánicos e inorgánicos que conforman el planeta. La nueva concepción de sí mismo del ser humano, concientiza la necesidad de conservar la naturaleza para conservarse a sí mismo. Reconoce el ejercicio de la frugalidad y de una relación con los otros, incluyendo las generaciones futuras, basada en el reconocimiento mutuo y la referencia al cuidado del ecosistema. Esta nueva visión de sí, significa un paso de la racionalidad instrumental hacia la racionalidad ética-vinculante con el mundo. 


\section{REFERENCIAS}

Benedicto XVI (2010). Mensaje para la Jornada Mundial de la Paz, 11: AAS 102, 48.

Benedicto XVI (2009). Carta encíclica Caritas in veritate (29 junio 2009), 66: AAS 101, 699.

Conferencia Episcopal Boliviana, (2012). Carta pastoral sobre medio ambiente y desarrollo humano en Bolivia. El universo, don de Dios para la vida. La Paz.

EFE (2016, 22 de abril). Un número récord de países firma en la ONU el acuerdo contra cambio climático. Recuperado de http:// www.efe.com/efe/america/ sociedad/un-numero-recordde-paises-firma-en-la-onu-elacuerdo-contra-cambio-climatico/20000013-2904899

Falconí, F. (2011). Sobre el desarrollo y la transición a la sustentabilidad. En Altmann, J., Beirute, T., Falconí, F. y Rojas Aravena F. (Coords.) América Latina y el Caribe: Perspectivas de desarrollo y coincidencias para la transformación del Estado. Informe preparado por la Secretaría General de FLACSO para la XXI Cumbre Iberoamericana (pp. 121-136). San José: Flacso.

Guardini, R. (1958). El ocaso de la Edad Moderna. Madrid.
Heidegger, M. (1988). Ser y tiempo. Traducción, prólogo y notas de Jorge Eduardo Rivera. Valparaíso: Universidad Católica de Valparaíso. En http://www.afoiceeomartelo. com.br/posfsa/Autores/Heidegger,\%20Martin/Heidegger\%20 -\%20Ser\%20y\%20tiempo.pdf

IPCC (2001). Cambio climático 2001: Mitigación. Informe del Grupo de trabajo III del Grupo Intergubernamental de Expertos sobre el Cambio Climático. Resúmenes del Grupo de Trabajo III. En http://www. grida.no/climate/ipcc tar/vol4/ spanish/pdf/wg3sum.pdf

Leff, E. (2000). La complejidad ambiental. México: Siglo XXI Editores.

Leff, E. (1994). Ecología y capital. Racionalidad ambiental, democracia participativa y desarrollo sustentable. México: Siglo XXI Editores/UNAM. Mahnke, E. y S. Götze (2015). Exportschlager Emissionshandel. Movum. Briefe zur Transformation. Oktober, 13.

Müller, M. (2015). Das Zeitalter des Menschen. Movum. Briefe zur Transformation. Februar, 4.

movum. Briefe zur Transformation. (2015). Das Anthropozän. Die Erde in der Menschenzeit. Februar, 4-7.

movum. Briefe zur Transformation. (2015). 
Nachrichten. Februar, 10.

ONU (2016). Objetivos de desarrollo sostenible. Combatir el cambio climático. Recuperado de http:// www.un.org/sustainabledevelopment/es/combatir-el-cambio-climatico/

ONU (1992, 14 de junio). Declaración de Río sobre el medio ambiente y el desarrollo.

Papa Francisco (2015). Carta encíclica Laudato si'. Vaticano: Tipografía Vaticana.

Reimer, N. (2015). Die 100-Milliarden-Dollar-Frage. Movum. Briefe zur Transformation. Oktober, 14.

Schlegelmilch, K. (2015). Umweltschädliche Subventionen vereiteln wirk- samen Umweltschutz. Movum. Briefe zur Transformation. Oktober, 8.

Staude, J. (2015). Das unschätzbare Schätzen lernen. Movum. Briefe zur Transformation. Oktober, 12.

Steffen, W. et al. (2015). Planetary boundaries: Guiding human development on a changing planet. Science 347. DOI: 10.1126/science.1259855.

Ulrich, P. (2008). Ética económica integrativa. Fundamentos de una economía al servicio de la vida. Trad. L. A. Panchi. Quito: Abya-Yala. 